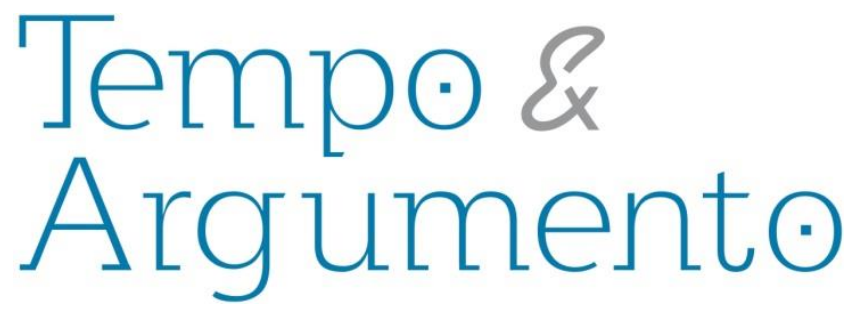

\title{
Tecidos, linhas e agulhas: uma narrativa para Zuzu Angel
}

\begin{abstract}
Resumo
Na década de 1960, enquanto a moda brasileira seguia os padrões europeus, Zuzu Angel proclamava, entre chitas e rendas, "eu sou a moda brasileira". O conteúdo do texto versa sobre a identificação das contribuições da produção estética de Zuzu Angel na criação de representações para a moda brasileira e também sobre a apropriação de tecidos pouco nobres, de panos usados para a decoração do lar e de trabalhos manuais de linha e agulha na construção de roupas feitas para a elite, o que se constitui em exemplo de reaproveitamento na moda. A metodologia utiliza as roupas como textos-documentos para a narrativa de sua trajetória. Associados à história da moda, das mulheres e aos conteúdos do filme "Zuzu Angel", desvendamos aspectos da cultura feminina em suas relações com as domesticidades, a vida pública e política nos conturbados anos 1960 e 1970. Com tecidos, linha e agulha, Zuzu escreveu uma história na moda e na luta contra a ditadura civil-militar.
\end{abstract}

Palavras-chave: ANGEL, Zuzu, 1976; Roupas; Moda - Brasil; Política.

\section{Ivana Guilherme Simili}

Doutora em História pela Estadual Paulista Júlio de Mesquita Filho - Unesp (Assis). Professora do Programa de Pós-Graduação em História da Universidade Estadual de Maringa - UEM. Brasil

ivanasimili@ig.com.br

\section{Débora Pinguello Morgado}

Mestranda do Programa de Pós-Graduação em História da Universidade Estadual de Maringa - UEM. Brasil deborapmorgado@hotmail.com

\section{Para citar este artigo:}

SIMILI, Ivana Guilherme; MORGADO, Débora Pinguello. Tecidos, linhas e agulhas: uma narrativa para Zuzu Angel. Revista Tempo e Argumento, Florianópolis, v. 7, n.15, p. 177 - 201. maio/ago. 2015.

DOI: 10.5965/2175180307152015177

http://dx.doi.org/10.5965/2175180307152015177 


\title{
Fabric, thread and needles: a narrative for Zuzu Angel
}

\begin{abstract}
In the 1960s, while the Brazilian fashion followed the European standards Zuzu Angel proclaimed, between chintz and laces, "I am the brazilian fashion". The text content consists on identifying Zuzu Angel aesthetic production contributions in the creation of brazilian fashion representations and also about the appropriation of not so noble fabrics, of cloths used for home decoration and of thread and needle handicrafts in the construction of clothes made for the elite, which constitutes an example of reuse in fashion. The methodology uses the clothes as textsdocuments to the narrative of its trajectory. Linked to the history of fashion, women and the contents of the movie "Zuzu Angel", we unravel aspects of female culture in its relationship with the domesticity, public and political in the troubled 1960 s and 1970s with fabrics, thread and needle, Zuzu wrote a history in fashion and in the fight against the civil military dictatorship.
\end{abstract}

Keywords: ANGEL, Zuzu, 1976; Clothes; Fashion -

Brazil; Politics.

\section{Introdução}

A trajetória das mulheres na moda permite captar e entender os meandros percorridos por uma personagem no seu relacionamento com a produção de roupas, como mecanismo engendrado para vestir e significar sua história de vida. Esta é a abordagem proposta para Zuleika Angel Jones, conhecida como Zuzu Angel. Mineira da cidade de Curvelo e nascida em 5 de junho de 1921, ficou conhecida na memória do estilismo brasileiro, por seu pioneirismo, como primeira designer de moda brasileira. 
$\mathrm{Na}$ construção desse pioneirismo, como produção de significados para uma trajetória pessoal e social, está o fato de que foi a primeira mulher a ocupar um espaço no universo da moda brasileira nos anos 1960, momento em que as principais referências eram os homens que, como costureiros, tinham destaque e fama. Soma-se a este aspecto, a representação da educação feminina observada em Zuzu que, no início do século XX, promoveu o domínio das artes de linha e agulha pelas mulheres.

Com estes conhecimentos, construiu um percurso que vai da costureira à estilista renomada que conquista reconhecimento nacional e internacional, extrapolando as fronteiras nacionais, tornando, assim, conhecida e reconhecida a moda brasileira internacionalmente. Finalmente, o percurso desta mulher, como mãe e esposa, fornece pistas de um modelo hegemônico - casar e ter filhos - e de como ele foi rompido com o divórcio e o sofrimento pela captura do filho pelo regime militar nos anos 1960.

De um lado, a ruptura com o casamento transforma-se em ingrediente que alavanca sua trajetória profissional e a projeta. De outro, a posição de poder desfrutada como estilista renomada permite-lhe transformar a moda em instrumento político. $\mathrm{O}$ desaparecimento e morte do filho, Stuart Edgar Angel Jones, em 1971, pela ditadura civilmilitar, modifica a sua relação com a história política brasileira mediante sua inserção na luta contra o regime. A instrumentalização das roupas para denunciar e protestar a morte do filho permite caracterizar a moda praticada pela personagem como política.

A noção de política é polissêmica e, como tal, abrange uma gama imensa e variada de práticas e representações (CHARTIER, 1995) desenvolvidas pelas pessoas no decorrer de uma trajetória de vida. Destarte, a política não se restringe às esferas do Estado e de suas instituições. Ela integra várias dimensões da vida cotidiana, está contida nas múltiplas relações pessoais, nas simbologias e nas representações elaboradas pelos grupos sociais e políticos (PRADO; FRANCO, 2012).

Ao usar as roupas como linguagem simbólica para denunciar o crime cometido pela ditadura civil-militar, ao matar e ocultar o corpo de seu filho, Stuart Edgar Angel Jones (11.01.1946-14.06.1971), um jovem na faixa etária dos 20 anos, a mãe e a estilista rompia com o silêncio e a cultura do medo que marcavam a relação da sociedade civil com o 
A relevância dessas "vozes" para entender as dinâmicas e os matizes da história da ditadura civil-militar no Brasil reside no apoio de amplos setores da sociedade civil ao golpe militar em 1964 e sua ulterior instauração e consolidação. Embora

[...] seja inegável o protagonismo da cúpula das Forças Armadas, sobretudo do Exército, no vitorioso golpe de estado iniciado no dia 31 de abril de 1964 e na posterior instauração e consolidação da ditadura civilmilitar, a relativa facilidade da vitória dos militares golpistas seria impensável sem o apoio de amplos setores da sociedade civil liderados pelos políticos conservadores, empresários e fazendeiros, entre outros atores e instituições, pela maioria dos membros da hierarquia da Igreja Católica e pelos meios de comunicação de massa. (PETIT; CUÉLLAR, 2012, p. 170)

O significado da voz que marcou a atuação política de Zuzu, por meio da linguagem que dominava - a de costurar e bordar tecidos para a produção de roupas -, ganha outros contornos quando se considera que, conforme apurado pela Comissão Nacional da Verdade, cinco anos após a morte do filho, ela se torna vítima do regime que combateu. Portanto, Zuzu e suas roupas são testemunhas históricas dos mecanismos de tortura e morte engendrados pela ditadura civil-militar, constituída em duas fases, no longo período de duração que vai do golpe, em 1964, até 1989, quando ocorre a transição do regime ditatorial-militar para um regime liberal-democrático (o governo Sarney de 1985-1989), assim determinadas por Codato (2005). Durante o período, entre 1969-1974 ocorreu a consolidação do regime ditatorial-militar, que coincide com o governo Médici; e durante 1974 e 1979, houve a transformação do regime ditatorial-militar no governo Geisel.

Em 1968, as políticas do Estado de censura à imprensa e de torturas a civis foram sofisticadas com a instauração do DOI-CODI (Destacamento de Operações de Informações - Centro de Operações de Defesa Interna) e o Ato Institucional n 5 (Al-5). Houve renovação nos esquemas repressivos e a ampliação dos alvos: os jovens que, além dos sindicalistas e dos trabalhadores rurais, eram os filhos dos políticos, os estudantes e 
Por conseguinte, a produção estética-visual de Zuzu desenvolvida como textodenúncia e testemunho histórico do que foi feito com a juventude brasileira e com as mães dos moços e das moças que tiveram suas vidas dizimadas pela repressão militar, constitui-se num dos pontos marcantes de seu percurso como estilista.

Para entender o significado da moda política/denúncia/protesto como elemento integrante de um percurso pessoal e profissional, optamos por adotar neste texto uma das faces do pioneirismo de Zuzu Angel, a qual está contida e foi determinante nas suas ações como estilista quando ocorre a morte do filho: as inovações introduzidas na criação de moda por meio do aproveitamento de materiais têxteis e a valorização dos bordados nas coleções de roupas. Estes são aspectos que a distinguiram, projetaram-na no mercado nacional e internacional, e lhe proporcionaram as condições de denunciar no exterior o que o Brasil estava a fazer com os jovens: matando-os.

Nos vários pioneirismos de Zuzu, revelam-se os laços que ela estabelecia com uma espécie de cultura feminina e das mulheres nas relações históricas e políticas com os trabalhos manuais, para escrever com os conhecimentos acumulados, por meio de agulhas e linhas, suas histórias de vida, e assim testemunharem suas experiências de luta.

Antes de Zuzu, em 1935, sob o regime do governo Vargas, uma jovem militante comunista, Genny Gleizer, presa pela polícia paulista quando ainda era menor de idade, e transferida sucessivas vezes de presídio, deixou como registro de passagem pelo Rio de Janeiro uma toalha bordada durante sua condição de prisioneira. A toalha, como parte do acervo do Arquivo Público do Estado do Rio de Janeiro (APERJ), transformou-se em diário, por meio do qual a escritora dribla as vigilâncias e controles, usando em vez de lápis, as agulhas para escrever sobre o tecido. Nela, registrou: “Hoje fazem 40 dias que estou preza" (ARRUDA, 2010, p. 16).

As roupas de Zuzu Angel, como a toalha de Genny Gleizer, são "escritas de si" (GOMES, 2004, p. 4) sobre tecidos. Enquanto a toalha se constitui em testemunho 
maneiras de uma mulher lidar com a vida e produzir roupas, incorporando as transformações que acometem os percursos individuais em conteúdos narrativos estetizados. Escritos que incorporam as mudanças e se exprimem em textos-roupas criados com os saberes e fazeres históricos de mulheres com panos e linhas.

Com alguns destes textos-roupas, narramos a trajetória de uma mulher/mãe/estilista. Como tais, foram concebidos como escritas femininas sobre tecidos que veiculam conhecimentos e ensinamentos de moda. Concordamos e adotamos na abordagem de nossa estilista a ótica de Carino (1999, p. 103), segundo a qual "As construções biográficas contêm uma instrumentalidade educativa, podendo ser apreciadas no contexto de uma pedagogia do exemplo". Pressupomos, portanto, que o contato com os escritos de moda produzidos por Zuzu, traduz maneiras de lidar com a vida e produzir roupas, que são aprendizados acerca de como aproveitar e valorizar os saberes e os fazeres históricos de mulheres com panos e linhas.

São as referências nacionais que ela incorporou nas roupas, por meio de tecidos e panos de vestir a casa, que matizamos, com vistas a entender as contribuições da estilista na produção de significados para a moda nacional, os conceitos que se articulavam com o aproveitamento da cultura dos tecidos e reaproveitamento de bens simbólicos que são os artigos têxteis da casa - colchas, toalhinhas bordadas e rendadas que enfeitavam os móveis e objetos domésticos.

A perspectiva teórica e metodológica de transformar o percurso da estilista em recurso para a compreensão das rupturas e das redes de significação por ela fabricadas, na e para a moda brasileira, estão apoiadas em concepções biográficas que rompem com a premissa de que uma vida é linear e tem ritmo constante, que há coerência e racionalidade no itinerário das pessoas que escolhemos estudar. Como diz Soihet (2003), qualquer análise biográfica deve considerar e equilibrar a abordagem de uma personagem, considerando o vai e vem em que o dado e o vivido de uma vida, como os movimentos constantes em que as determinações e as margens de manobra têm peso e 

coletivos" (SOIHET, 2003, p. 47).

Portanto, a proposta de abordagem biográfica para Zuzu Angel sob o foco da moda permitirá dimensionar, nas escolhas de caminhos de suas criações, as rupturas e os encaminhamentos que a posicionaram como uma das representantes da moda nacional, com perfil e estilo inovador, marcadores por meio dos quais ela se dá a ver e a conhecer nos documentos de cunho biográfico - memórias fílmicas, pessoais e literárias - em específico, as narrativas de moda. O texto será apresentado em quatro eixos que descrevem a trajetória de Zuzu no início de sua carreira; sua relação com o reaproveitamento; o feminismo em seus discursos de moda; e, por fim, a construção de uma estética jovem voltada para o protesto político e o embate com o regime militar.

\section{Cortes e costuras de moda}

Na década de 1960, enquanto a moda brasileira seguia os padrões da moda europeia, executada pelas mãos dos grandes estilistas, emergem no cenário nacional alguns nomes masculinos como costureiros famosos, por exemplo, Clodovil e Dener. Ao mesmo tempo, uma mulher - figura mais ligada à costura doméstica -, rompendo com os modelos europeus na produção de roupas, diz: "eu sou a moda brasileira”. Zuleika Angel Jones ou, como conhecida popularmente, Zuzu Angel, intitulou-se a primeira designer de moda do Brasil.

Como entender a definição que ela criara? Qual o significado dela no contexto da moda brasileira, momento em que ocorrem investimentos na criação do mercado brasileiro de roupas? Talvez, a explicação esteja em seu percurso, nos aprendizados da costura pela garota pobre e simples que aprendia a aproveitar tecidos e acumular conhecimentos sobre roupas. Se buscarmos entender o conceito de design, perceberemos que a ele associa-se o valor emocional que o designer consegue dimensionar em seu produto (NORMAN, 2008), e um exemplo disso é o 

conquistado fama e poder no universo da moda. Ela conseguiu visibilidade como estilista numa época em que o fazer moda, no contexto nacional e internacional, era predominantemente masculino. Antes dela, somente Coco Chanel e Elsa Schiaparelli haviam conquistado lugar de destaque em meio aos homens, como Dior e Yves Saint Laurent, expoentes da moda internacional e que se destacavam no Brasil junto com os brasileiros que, entre os anos 1960 e 1970, procuravam criar uma identidade para moda brasileira, definida como roupas feitas por brasileiros e para as brasileiras. No período, costureiros como Dener, Clodovil e José Ronaldo fizeram vários investimentos em propagandas, desfiles e parcerias com empresas nacionais e multinacionais para se projetarem no Brasil e no exterior (DURAND, 1998).

Zuzu Angel passou boa parte da vida em Belo Horizonte e desde pequena se dedicou a costurar, como era costume entre as mulheres da época. Ela fazia roupas para si e, mais tarde, depois do casamento com o norte-americano Norman Angel, para os filhos Stuart Edgar, Ana Cristina e Hildegard Beatriz. Em uma matéria publicada no ano de 1972, Zuzu Angel foi apresentada como “[...] mineira de Curvelo, com oito anos já costurava e inventava moda para ela e para as irmãs. Aos 17 anos foi campeã sulamericana de natação e há 15 anos costura profissionalmente" (SILVA, 2006). E como afirmava a própria Zuzu Angel, aprendeu a costurar praticamente por si própria e seu primeiro vestido surgiu sem que ela esperasse por isso.

Em 1947, a estilista se muda para o Rio de Janeiro e passa a costurar uniformes destinados a crianças carentes para a Obra das Pioneiras, ação beneficente liderada por Sarah Kubitschek - então primeira dama brasileira e amiga de uma de suas tias. Com o tempo, Zuzu fez contatos com mulheres cariocas da elite e começou a costurar para elas em seu próprio apartamento.

Na leitura de Prado e Braga (2011), no período, o tipo de roupa que ela mais costurava eram saias que vieram a se transformar em representativas de sua moda. As 
A criatividade da costureira, sem dúvida, é um aspecto que explica a sua transformação em estilista renomada. Ela experimentava tecidos considerados pouco nobres na confecção de roupas femininas, caso do zuarte, um tecido barato de algodão, rústico e com a trama feita de fios brancos e azuis, destinado ao forro de colchões. Com esse tecido e seu toque pessoal ela conseguia fazer saias com originalidade e personalidade e sua fama fez com que seu negócio recebesse o nome de "Zuzu Saias" (PRADO; BRAGA, 2011). Ainda de acordo com as narrativas de seu percurso, o sucesso das saias fez com que se iniciasse o processo de contratação de ajudantes, expandindo, assim, a produção, que também foi impulsionada pela confecção de blusas, cujos detalhes de destaque eram as golas feitas dos mais diversos tipos de modelagem.

Em 1961, a mulher que começava a ser bem sucedida na vida profissional separouse do marido e tornou-se responsável por cuidar dos filhos e de prover o sustento do lar. Por passar algumas dificuldades no início da separação, os tecidos mais baratos foram boa opção para o feitio das saias, o que nunca foi mal visto por suas clientes já que era conferida originalidade às peças, sempre muito bem decoradas.

Mesmo com algumas dificuldades, mas com muito esforço, a fama da costureira crescia constantemente e, em pouco tempo, no ano de 1966, Zuzu pôde realizar seu primeiro desfile no $2^{\circ}$ Salão de Moda da Feira Brasileira do Atlântico. No mesmo ano, desfilou uma coleção no Clube de Decoradores do Copacabana Palace.

Ao mesmo tempo em que Zuzu iniciava sua carreira de sucesso na moda, observase um fato inédito: a consolidação da moda brasileira. Os estudos sobre a moda no Brasil concordam com um ponto, foi nos anos 1960 que se consolidou um campo de produção e consumo de roupas, que teve na juventude um dos suportes para fazer girar os seus motores de funcionamento. De maneira abrangente é o que assevera Bonadio (2010) e é o que dizem Moutinho e Valença (2005, p. 190), "O surgimento da moda nacional e prêt-àporter refletia as aspirações da juventude". As indústrias de confecção, sintonizadas com 
Naqueles anos observa-se também a popularização da alta-costura, da roupa sob medida e para clientes especiais, entenda-se por isso, que pagavam pela exclusividade de peças únicas. Seguindo as dinâmicas da moda, nas décadas de 1960 e 1970, Zuzu investe no prêt-à-porter, o qual é pautado no conceito do "gostou, levou". Ela associa o trabalho de roupas exclusivas com as prontas, vendendo-as em sua boutique, outro fenômeno da época, espaço direcionado para o consumo da elite, no caso, a carioca (DURAND, 1998).

Foi também na década de 1960 que Zuzu investiu na divulgação de suas roupas no cenário internacional. Em 1968, ela apresentou suas roupas na feira de Santo Antônio, no Texas. O evento foi noticiado no The New York Times. A conquista da fama pela brasileira fez com que fosse homenageada no Brasil como mulher destaque do ano. Com suporte nas pistas legadas por Zuzu, é possível dizer que ela e sua moda foram mais conhecidas nos Estados Unidos que no Brasil. Noutro sentido, o percurso da estilista fornece pistas sobre como uma costureira soube identificar e aproveitar os conhecimentos e habilidades concebidas pela sociedade e cultura dos anos 1940 a 1970, como "naturais ao feminino", para fabricar uma história profissional com destaque social e fama.

Enquanto as perspectivas profissionais de Zuzu se ampliavam, o filho Stuart envolveu-se na militância do Movimento Revolucionário 8 de Outubro (MR-8). O filme "Zuzu Angel" (2006) é uma narrativa de como a sua trajetória profissional sofre mudanças com a militância e a subsequente morte do filho pela ditadura civil-militar implantada no Brasil, em 1964, com o golpe militar.

Um dos aspectos marcantes do filme é a maneira como a estilista se apropriou da moda para transformá-la em elemento de crítica política. Nesse aspecto, o desfile de sua coleção no International Dateline Collection III - Holiday and Resort na residência do cônsul brasileiro em Nova lorque, em setembro de 1971, é emblemática. Sua produção foi incrementada com os símbolos de seu luto, de sua dor e da dor que sofreu seu filho. Eram conhecidas do público de Zuzu as estampas floridas e coloridas, mas neste desfile a passarela foi invadida por pássaros em gaiolas, balas de canhão, tanques, quepes, 
pombas negras e anjos mortos. Foi então que os anjos passaram a predominar em todas as suas coleções posteriores. Ao fim do desfile, Zuzu surge na passarela com veste fúnebre, crucifixos na cintura e um anjo de porcelana no pescoço.

\section{Os fios culturais tecendo a trajetória da designer}

A trajetória de Zuzu Angel como narrada no texto pode ser concebida como pedagógica (CARINO, 1999) porque possibilita conhecer e aprender como uma mulher se relacionou com a moda, por meio de sua experiência de vida, tornando-a expressiva da cultura do aproveitamento que permeia a relação das mulheres com a casa e a vida doméstica.

Para pensarmos a criação de visualidades e a conferência de características e representações para a moda brasileira, é interessante avaliar a relação de Zuzu Angel com a renda nordestina e principalmente com a chita. Para tal, foi necessário visitarmos a história da chita, o tecido de algodão de tramas abertas e cores primárias. Não há dúvidas de que um dos elementos mais representativos da cultura brasileira é a chita, que se faz presente principalmente nas vestes e na decoração das festas de São João - festa tipicamente brasileira e que traz representações de uma cultura de interior, dos caipiras.

Em coincidência com a história de Zuzu Angel, a primeira empresa a fabricar a chita no Brasil se situava na cidade natal da estilista - Curvelo - e até o ano de 1961 dedicou sua produção têxtil exclusivamente à chita. O tecido barato era considerado o "primo pobre da finíssima cambraia de algodão" e no comércio francês era destinado principalmente aos africanos (GARCIA, 2010). A chita (tecido com largura padrão e flores grandes), a chitinha (estampada com flores pequenas) e o chitão (tecido de largura superior ao tamanho padrão e com flores grandes), eram muito utilizados como forros de colchão, aventais e outros têxteis domésticos, e para as vestes dos mais pobres. Diferente de outros países, o Brasil adotou a chita e suas variações como um tecido que pode e deve estar nas passarelas dos eventos de moda. O valor destinado ao tecido no campo da moda e toda a representação que conferiu à moda brasileira, principalmente do ponto de vista do olhar estrangeiro tem uma precursora, que é Zuzu Angel. 
As saias mais emblemáticas de Zuzu eram feitas com chita ou tecidos de estampas semelhantes. Os penduricalhos e rendinhas das saias, combinados com as blusas que deixavam a barriga à mostra e desobrigavam o uso do sutiã, se transformaram, na época, no ideal de uma aparência jovem, feminina e brasileira.

Assim como a chita, a renda nordestina fabricada no Ceará, conhecida como renda de bilro, foi promovida a item de luxo também pela criatividade de Zuzu Angel. Até a década de 1960, essa renda era destinada aos panos de cozinha, mas Zuzu tingiu as rendas na cor de tecidos nobres e aplicou sobre suas roupas, o que foi motivo de choque para muitas pessoas. Uma de suas peças mais referenciadas era um vestido de noiva todo construído de renda de bilro, com quadrados de organza e flores no centro de cada quadrado. A Figura 1 mostra o vestido que foi produzido para uma loja americana no ano de 1972.

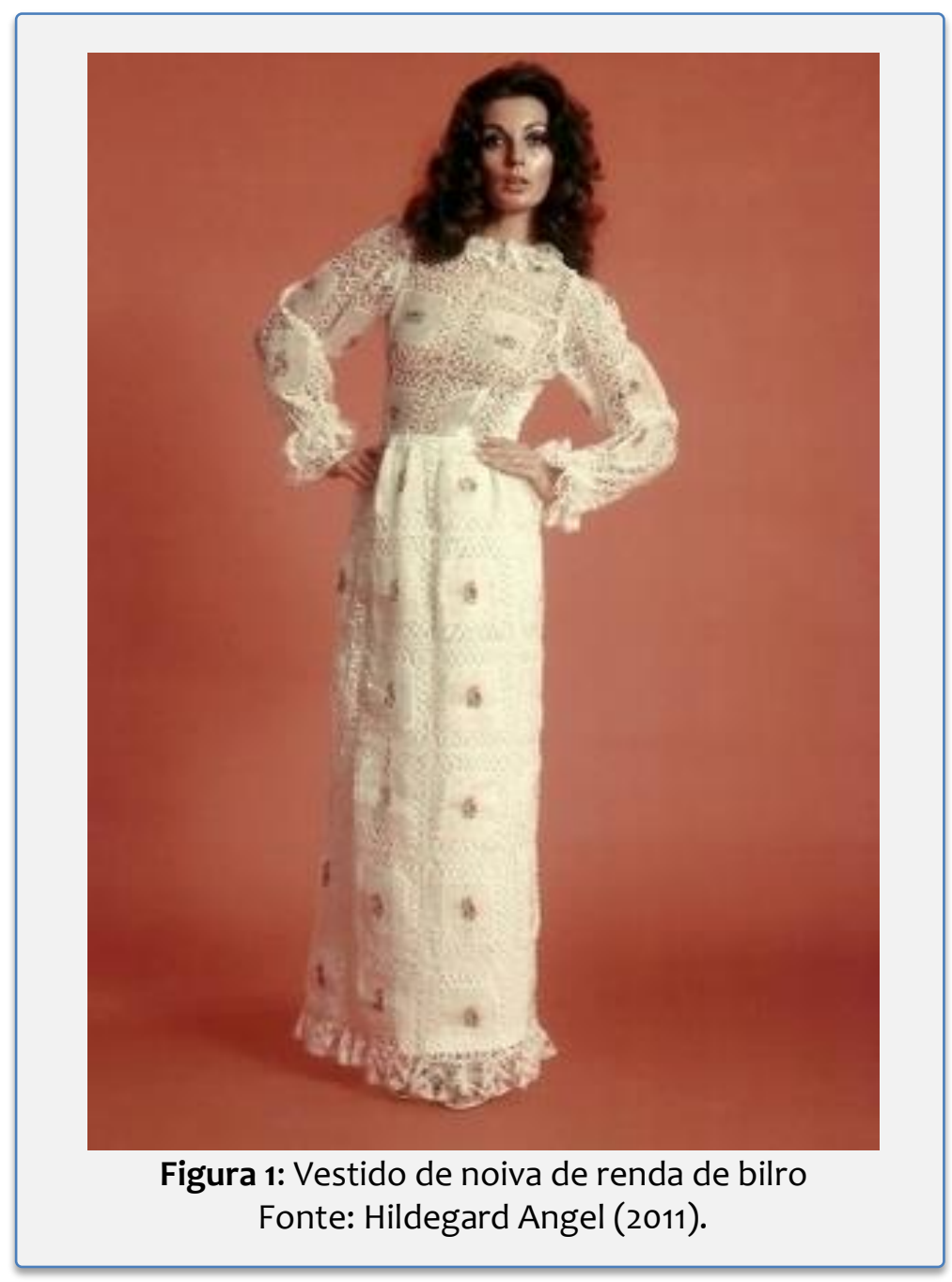


Desde a época de Zuzu até os dias atuais, a renda nordestina tem sido utilizada na moda brasileira - que também é exportada - em vestidos de luxo e de preço alto, como é o caso das roupas da estilista Martha Medeiros que em sua loja online possui vestidos de até $\mathrm{R} \$ 15.000,00$ (FARFETCH, 2014). É fato que Zuzu Angel impôs, com sua originalidade, os rumos que a moda brasileira tomaria a partir dela.

Dos caminhos percorridos por Zuzu em sua trajetória como designer, podemos dizer que sua face mais interessante e exemplar foi o reaproveitamento de têxteis domésticos na construção de roupas que vestiram mulheres pertencentes à elite. Perceber o olhar que Zuzu lançou aos paninhos, às toalhas de mesa é inspirador para qualquer criador que pode vir a descobrir em si um grande potencial para transformar tecidos e objetos e assim contribuir com o meio ambiente, com o descarte e com o consumo desregrado.

Nesse aspecto, entramos um pouco nas discussões sobre memória. Hall (1992) fala sobre a importância da memória como meio de cada indivíduo estabelecer nexos com o passado e assim conhecer a própria história para alocar-se melhor no mundo. Quantas mulheres não guardam em suas gavetas os tecidos que compuseram outrora seu enxoval? É possível pensarmos que falte a essas mulheres e a seus descendentes o olhar para tais tecidos a fim de buscarem um pouco da própria história. Seguindo o exemplo de Zuzu, que usava toalhas de mesa na construção de vestidos, é possível pensar também no uso dos panos que constituem parte de uma história de vida em roupas que dirão muito mais sobre uma identidade que as roupas compradas nas grandes redes de fast fashion.

Ao mesmo tempo em que as roupas são uma extensão do corpo, não mais é possível desvendar a personalidade de alguém por meio de sua roupa (AVELAR, 2011). E se hoje ainda existem as roupas de outras décadas e outros tempos para que sejam tocadas e revividas, não é possível esperar o mesmo para o futuro. Visualizar um futuro sem roupas e tecidos do passado é cada vez mais possibilitado graças à produção feita para o descarte, uma produção que enaltece as novidades em detrimento a tudo que esconda um passado (LIPOVETSKY, 2009). Entendemos, então, que a prática exercida por Zuzu Angel ao alocar os têxteis domésticos em peças de vestuário é exemplar do ponto de vista de mostrar uma maneira de vestir no corpo alguma história, e também do ponto 

traz a fotografia de um dos mais famosos vestidos feitos pela estilista. Um vestido de noiva que tem como matéria prima principal uma toalha de mesa, revestida de organza e bordados coloridos e elegantes, que ajudam a representar o gosto da brasileira.

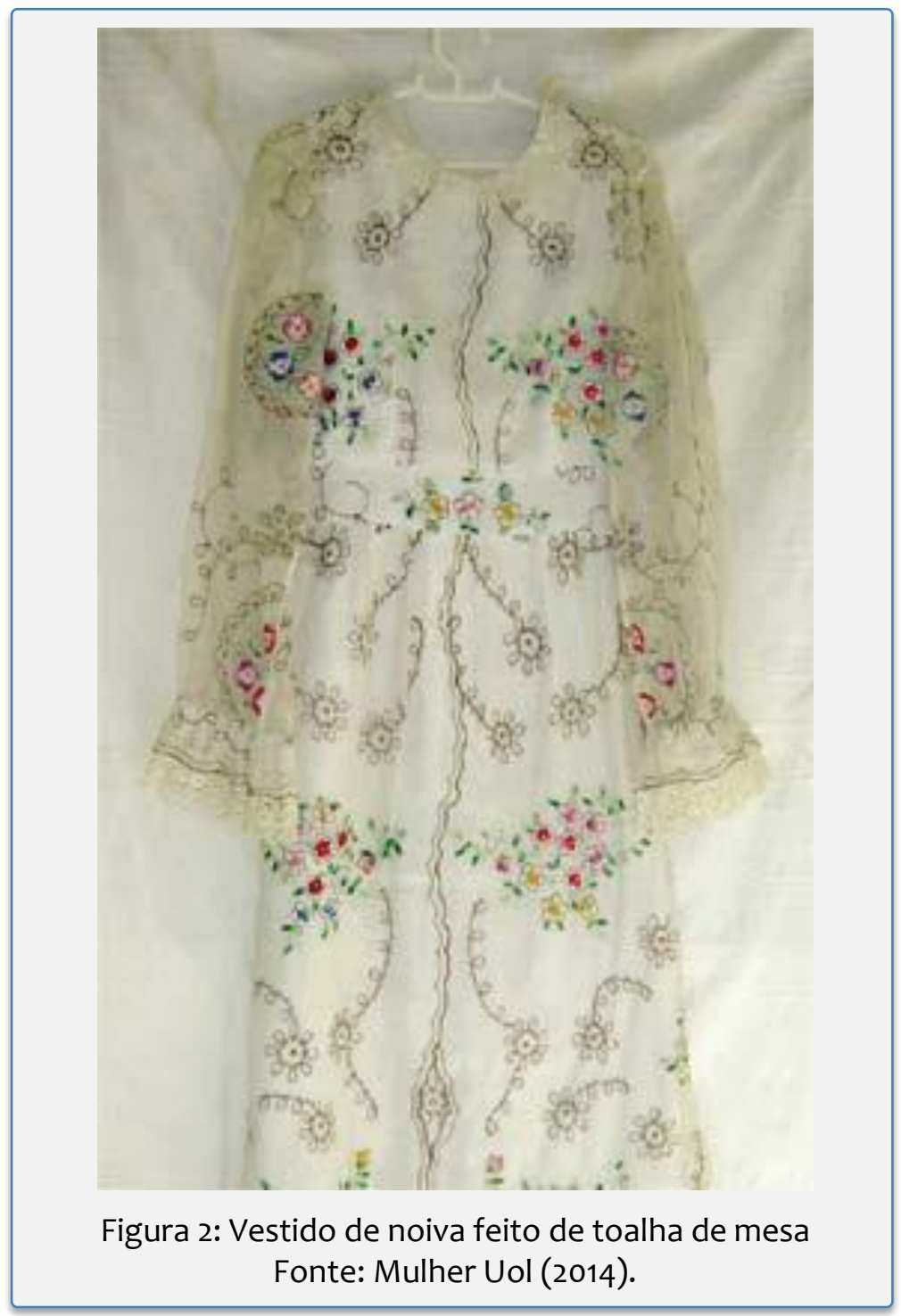

O reaproveitamento e o uso da chita sem dúvidas são os maiores marcadores de que Zuzu foi mesmo a primeira a conferir brasilidade à moda criada por brasileiros. Mais interessante ainda é perceber como estes usos se conectaram à história das mulheres e alavancaram a trajetória da designer do protesto e do feminismo. 


\section{A história das mulheres para uma moda feminista}

Simmel (2008), ao explicar a relação das mulheres com a moda, afirma que, devido ao aprisionamento feminino decorrente da autoridade masculina exercida desde sempre, as mulheres tendem a gostar e se apegar aos costumes e a "tudo o que fica bem". A moda, os objetos, os panos da casa ajudavam a projetar a mulher como boa esposa, boa mãe ou moça recatada e que "serve" para o casamento.

Como a história das meninas no Brasil revela, desde o século XIX, logo nos primeiros anos de vida, as garotas eram apresentadas aos trabalhos e artes manuais, como os bordados, confecções de rendas e costuras, pelas mãos das mães e das tias. Esses conhecimentos eram direcionados para a preparação do enxoval - lençóis, toalhas de mesa e roupa branca. A esses conhecimentos e habilidades manuais, somavam-se os aprendizados musicais, em particular, o piano, concebido à época como necessário para que, como esposa, pudesse bem recepcionar, comportamento tido como refinado para as mulheres e esposas da elite (AREND, 2012).

A história feminina, como bem contada por Perrot (1989, p. -6) ainda nos revela com que apreço pequenos tesouros eram guardados:

As mulheres tem paixão pelos porta-joias, caixas e medalhões onde encerram seus tesouros: mechas de cabelo, joias de família, miniaturas que, antes da fotografia, permitem aprisionar o rosto amado. Mais tarde, fotografias individuais ou de família, em porta-retratos ou em álbuns, esses herbários da lembrança, alimentam uma nostalgia indefinidamente declinada. [...] A roupa de cama, mesa e banho, o vestuário constituem uma forma de acumulação. O enxoval cuidadosamente preparado nos meios populares, sobretudo rurais, é uma longa história entre mãe e filha. A confecção do enxoval é um legado de saberes e segredos do corpo e do coração, longamente destilados. O armário de roupa é ao mesmo tempo o cofre e o relicário.

Aprender a costurar e a bordar era de fato um evento muito importante para as mulheres até o início do século XX. Segundo Maleronka (2007), isso representava as manifestações e motivações do interesse feminino e traduzia as ocupações e modos de vida que foram construídos como meio de expressão de classe e de gênero nas relações sociais. 
Assim, as mulheres se tornaram o alvo da moda e, no início do século XX, na região Sudeste do Brasil, o alvo dos comerciantes de tecidos. No entanto, como a maioria das mulheres não possuía muitos recursos financeiros, os comerciantes de estabelecimentos populares vendiam tecidos mais baratos como as chitas, os fustões e o brim. Dentre estes estabelecimentos, podemos destacar as Casas Pernambucanas que vendia tecidos populares destinados às mulheres de classe média (MALERONKA, 2007).

Zuzu Angel, menina de classe média, assim como conta a história das mulheres brasileiras, também se prestou a aprender os dotes essenciais à concepção da feminilidade. No início do exercício da profissão de costureira, recorria às Casas Pernambucanas para a aquisição de tecidos mais baratos, como o zuarte e a chita, para o feitio de suas saias (PRADO; BRAGA, 2011).

Desde a Antiguidade, a mulher possui relação estreita com a linha e a agulha. $\mathrm{Na}$ demonstração de seu amor por Ulisses, Penélope, na obra escrita em VIII a.C. por Homero (2009), se entrega ao bordado durante o dia e o desfaz durante a noite, para que seja refeito no dia seguinte. Como averigua Maleronka (2007), no Brasil, datam do período colonial os indícios da relação da mulher com a tarefa de coser. No entanto, o que se percebe é que essa relação da mulher com a costura foi algo estritamente doméstico por muito tempo. O brilho das tesouras que produziam nobres vestidos e elegantes indumentárias masculinas provinha dos grandes costureiros que dominaram a produção de moda até o surgimento de Coco Chanel, que se impôs no mundo da alta costura na segunda década do século XX e apontava para um despertar feminista que viria a ocorrer algum tempo depois.

Assim, nos anos decorridos entre 1960 e 1970 ocorrem mudanças significativas nas relações dos gêneros, impulsionadas pelos movimentos feministas, além da comercialização da pílula anticoncepcional, pela maior escolarização dos segmentos femininos e pelo ingresso das mulheres no mercado de trabalho, que passam a ocupar postos e posições sociais, levando-as a desfrutar da independência financeira e a usufruir de posição de destaque na vida social, política, cultural. 
Para Bassanezzi (1993, p. 113-114), as transformações observadas no período foram impulsionadas, entre outros fatores, pelo desenvolvimento econômico, processo de urbanização e crescimento urbano, incremento do parque industrial, ampliação de possibilidades profissionais para a população em geral e para os segmentos femininos em particular. As mudanças teriam se refletido nas relações entre os gêneros, visto que, "Ao mesmo tempo em que discriminações de gênero se manifestam com intensidade, certas distâncias entre homens e mulheres se reduzem [...]". Nesse contexto, os papéis femininos tradicionais de mães, donas de casa e esposas, em função das características consideradas como próprias das mulheres, englobadas no termo feminilidade (pureza, doçura, resignação, instinto materno etc.), constituem-se no modelo hegemônico.

Por conseguinte, a abordagem do percurso profissional de Zuzu, uma mulher que rompe com o casamento, tornando-se desquitada, e a maneira como ela se posiciona diante de fatos políticos que penetraram em sua vida, tais como o envolvimento dela e do filho na luta contra a ditadura militar, ajudam a entender os nexos entre a moda e as políticas de gênero do período.

Inicialmente, pela necessidade de prover o sustento da família, Zuzu encarou dificuldades e preconceitos dentro do país para conseguir visibilidade internacional, e se tornou então um exemplo para as mulheres no que concerne ao uso da sabedoria feminina para conquistar poder no mercado de trabalho e vencer preconceitos de gênero.

Concebemos, assim, que Zuzu é um modelo a ser seguido por muitas mulheres, no sentido de levá-las a perceber que a moda pode ser um caminho para a conquista de espaço na sociedade, na cultura e na arte; que os saberes e fazeres femininos, tais como o de costurar, narram a história das mulheres e como tais, precisam ser conhecidos e valorizados. Se, historicamente, os segmentos femininos foram submetidos a várias espécies de controles e aos mecanismos de dominação masculina, as estratégias desenvolvidas pelas mulheres para usarem seus saberes e fazeres para romperem com a dependência e ocuparem espaços de poder e de prestígio tornam-se nítidas no percurso de Zuzu. 
Quando Zuzu afirmou “Eu sou a moda brasileira”, falava sobre fazer uma moda em que não importavam as características europeias e que valorizava de fato as mulheres brasileiras, sejam as que teciam renda no nordeste, as que se vestiam de chita ou as que bordavam e costuravam em suas casas. Ao mesmo tempo, Zuzu pensava em conferir uma característica libertária em suas roupas, pois se identificava com as lutas feministas que começavam a ganhar força. Assim, no ano de 1967 lançou uma coleção com o nome “Fashion and Freedom” (Moda e Liberdade) que trazia modelos leves e coloridos, com o espírito da jovem brasileira e com a barriga a mostra - ao serem usados deixavam a mulher livre para o não uso do sutiã. Zuzu, então, dialoga diretamente com as mulheres encarceradas aos trabalhos domésticos, pois utiliza muito das visualidades das produções e artesanatos, concebidos dos trabalhos caseiros de linha e agulha, para discursar sobre o feminismo.

\section{Moda jovem como textos-denúncia}

O significado político da mais famosa coleção de Zuzu, de 1971, a International Dateline Collection III, por meio da qual a estilista denuncia e reivindica o direito de punir os culpados pela morte do filho, pode ser dimensionado quando se consideram os mecanismos de censura que se seguiram ao golpe militar em 1964, sofisticando-se nos seguintes, até 1985 .

"Não houve uma censura durante o regime militar, mas duas. A censura da imprensa distinguia-se muito da censura de diversões públicas”, explica Fico (2004, p. 36) sobre uma das interpretações para o Golpe de 1964 e o fio condutor da argumentação segundo o qual, a censura da imprensa acompanhou o auge da repressão (quando se pensa em cassações de mandatos parlamentares, suspensões de direitos políticos, prisões, torturas e assassinatos políticos) que se verificou entre finais dos anos 1960 e início dos anos 1970. Em relação à censura de diversões públicas, o apogeu ocorreu no final dos anos 1970, quando houve os conflitos entre setores mais conservadores da sociedade e as questões relativas às mudanças comportamentais como o movimento hippie; a liberalização das práticas sexuais e as manifestações artístico-culturais das 
As questões pontuadas por Fico (2004) ganham novas dimensões quando associadas às mudanças sociais, culturais, econômicas e políticas que se tornam perceptíveis na moda durante os anos 1964 e a década de 1970, da qual Zuzu foi uma das signatárias.

Um importante marcador das mudanças foi o processo de "juvenilização" da cultura, que redefiniu o conceito de juventude e a sua incorporação na criação de imagens e representações definidoras de roupas e comportamentos caracterizadores da moda jovem, com os emblemas da rebeldia, contestação e ruptura com valores consagrados de corpo, sexualidade e aparências.

A invenção e a popularização da pílula anticoncepcional, por volta de 1962, marcaram o surgimento de novas concepções sobre o olhar para o corpo e a sexualidade. "A perspectiva de maior controle dos processos relativos à reprodução humana, conjuntamente com o discurso da contracultura, que preconizava a libertação sexual produziu efeitos sobre as práticas afetivas e sexuais das jovens" (AREND, 2012, p. 78).

Essas mudanças encontram nas roupas e aparências dos/as jovens um veículo de comunicação visual. Para Zimmermann (2013), a divulgação midiática pelas revistas da 'invasão britânica', liderada pelos Beatles e pela fervilhante Swing London, desenvolve o rock nacional, o qual, por seu turno, se relaciona ao surgimento de cantores como Roberto Carlos e Wanderléia. A esse aspecto, soma-se a influência do estilo de vida e a rebeldia dos jovens norte-americanos, divulgadas pelos filmes, acentuando o sentimento de que ser jovem e moderno era rebelar-se, mediante práticas visuais e de comportamentos que questionassem noções e conceitos constituídos sobre modos de ser e de vestir.

Amparados pelos meios de comunicação, inclusive pela televisão, a partir da segunda metade dos anos 1960, as roupas e os comportamentos dão sentido ao conceito de juventude. No período, o mercado de produção de roupas voltado a esse segmento 
Para os/as jovens da época, o período marcou a alteração no visual e nas aparências. Eles e elas passaram a se vestir com roupas próprias à etapa da vida, ou seja, às idades, rompendo, assim, a relação histórica de usarem e se parecerem com os pais e mães. A ruptura fundamentava o surgimento de concepções relativas à adolescência e à juventude (ZIMERMANN, 2013). Alimentava-se e era alimentado pelo prêt-à-porter que amplia suas redes de produção e consumo com tendências indumentárias que se renovam no mesmo compasso e ritmo do universo jovem.

Voltamos nosso olhar para a Coleção International Dateline Collection III. Em 1971, entre as opções de roupas para jovens, estavam aquelas criadas por Zuzu Angel. Na coleção, em particular, o que ela faz é estetizar e estilizar as experiências sociais e políticas vivenciadas pelos/as jovens do país em que as liberdades de viver e de se expressar conquistadas no início da década de 1960 estavam condenadas à morte nas prisões (daí os bordados das grades); aos esmagamentos de "anjos", símbolos dos/as jovens entre os quais estava seu filho, pelos tanques e fuzis do regime militar.

Talvez o que Zuzu tenha inaugurado com a moda política/denúncia/protesto é uma maneira de usar as roupas como recurso simbólico que foi incorporado pela sociedade e cultura para a organização e união das pessoas. Nesse aspecto, é importante lembrar que as tragédias envolvendo jovens pelas várias espécies de violências que os acometem na vida cotidiana hodierna, as manifestações coletivas ganham forma e cor por meio de camisetas estampadas com o nome e o rosto das vítimas. Como não pensar e não associar a moda política de Zuzu como um ponto na linha da instrumentalização de peças da indumentária jovem que são as camisetas na comunicação visual para a crítica social? 


\section{Considerações Finais}

A constituição das roupas de Zuzu como testemunhos de um percurso em seus entrelaçamentos com a história das mulheres, da moda e da política brasileira dos anos 1960 e 1970 possibilitou dimensionar os manejos e os aproveitamentos dos aprendizados com os panos, linhas e agulhas na elaboração de narrativas. Por meio delas, desvelamos os fios que ligam as mulheres à sociedade, à cultura e à política. Singularidade e generalidade compassaram nossa abordagem para a personagem.

Como ponto alto de um percurso, destacamos as concepções que norteavam a educação e a conduta das mulheres como femininas. Nelas, os enxovais, as roupas de cama, mesa e banho e as roupas íntimas são indicadores de como se perpetuava a transmissão dos aprendizados que asseguravam às jovens a entrada no universo familiar - universo esse que deveria ser compreendido e dominado. A religiosidade empregada no feitio de artesanatos em têxteis dizia muito da conduta feminina. Em uma época em que esse cenário era ainda uma realidade, principalmente nos meios rurais, uma mulher ganhar posição de destaque por realizar, sobreviver e se projetar por meio de um trabalho que deveria estar recluso ao ambiente doméstico, marca o início de uma revolução feminista no campo da moda.

Estudar a trajetória de Zuzu foi realmente apaixonante e instigante, principalmente pelo fato de ela ter ido muito além do que se esperava de uma estilista libertária. A luta da mãe contra a ditadura militar na busca pela verdade sobre o filho prescreveu um novo legado de conduta para a moda: a moda protesto. Antes mesmo dos punks se projetarem como os grandes difusores da moda como forma de protestar, era brasileira a mulher que teve a coragem de lançar um grito de dor em uma passarela.

Se para uma mulher já era difícil sobreviver da moda - que era antes um ofício masculino -, irritar e ameaçar os que estavam por trás da ditadura civil-militar por meio da moda caracterizou Zuzu Angel como uma mulher ousada e perigosa demais. Sua morte decorreu de sua coragem, no entanto é lembrada como um símbolo de luta e como um exemplo a ser seguido. 
Para as mulheres, o recado mais importante que nos deixa a trajetória de Zuzu é que se libertar das amarras impostas socialmente pode ser um fator decisivo na busca pela felicidade e na descoberta de novas paixões. A tradução para o presente dos antigos ofícios, como os bordados e as costuras, tende a manter viva a memória das mulheres do passado que tanto sofreram.

Já para quem estuda e produz moda ou atividades artísticas em geral, a mensagem deixada por Zuzu Angel é para que saibam usar a criatividade como meio de reaproveitar objetos e têxteis antigos, para que assim sejam valorizados os objetos que contêm uma história, que contribuem com a formação pessoal e, de maneira mais ampla, com a sociedade e o ambiente.

\section{Referências}

ANGEL, Hildegard. Zuzu Angel: a primeira a chutar a bola da brasilidade. 17 de ago. de 2011. Disponível em: < http://www.hildegardangel.com.br/?p=9035>. Acesso em: 31 de out. de 2014 .

AREND, Silvia Fávero. Trabalho, escola e lazer. In.: PINSKY, Carla Bassanezi; PEDRO, Joana Maria (Orgs.). Nova história das mulheres. São Paulo: Contexto, 2012. p. 65-83.

ARRUDA, Cláudia Maria Calmon. Memórias num bordado: traços de Genny Gleizer no Arquivo Público do Estado do Rio de Janeiro. Cadernos de Pesquisa do CDHIS. Uberlândia, v.23, n.1, jan./jun. 2010.

AVELAR, Suzana. Moda, globalização e novas tecnologias. Rio de Janeiro: Estação das Letras e Cores, 2012.

BASSANEZI, Carla. Revistas femininas e o ideal de felicidade conjugal (1945-1964). Cadernos Pagu, Unicamp, n.1, p. 111-148, 1993.

BONADIO, Maria Claudia. As modelos negras na publicidade de moda no Brasil dos anos 1960. In. COLÓQUIO DE MODA, VI, São Paulo, 2010. Anais.... São Paulo: AnhembiMorumbi, 2010. Cd room.

CARINO, Jonaedson. A biografia e sua instrumentalidade educativa. Educação \& Sociedade, ano XX, n. 67, ago. 1999. 
CHARTIER, Roger. Cultura popular: revisitando um conceito historiográfico. Estudos Históricos. Rio de Janeiro, n.16, p. 179-192, 1995.

CODATO, Adriano Nervo. Uma história política de transição brasileira: da ditadura militar à democracia. Revista de Sociologia e Política. Curitiba, n²5, p.83-106, nov. 2005.

COIMBRA, Cecília Mari Bouças. Reparação e Memória. Cadernos AEL (UNICAMP). Campinas, v.13. n.24/25, 2008.

DURAND, José Carlos. Moda, luxo, economia. SP: Babel Cultural, 1998.

FARFETCH. Nova coleção Martha Medeiros. Disponível em:

<http://www.farfetch.com/br/shopping/women/designer-martha-

medeiros/items.aspx\#ps=1\&pv=6o\&oby=1>. Acesso em: 31 de out. de 2014 .

FICO, Carlos. Versões e controvérsias sobre 1964 e a ditadura militar. Revista Brasileira de História. São Paulo, v.24, n.47, p.29-60, 2004.

GARCIA, Carol. Imagens errantes: ambiguidade, resistência e cultura de moda. Estação das Letras e das Cores: São Paulo, 2010.

GOMES, Angela de. Escrita de si, escrita da história: a título de prólogo.In: GOMES, Angela de. . (Org). Escrita de si, escrita da história: RJ: Editora FGV, 2004. p.7-24.

HALL, Stuart. A identidade cultural na pós-modernidade. Rio de Janeiro: D P \& A Editora, 1992.

HOMERO. Odisseia. São Paulo: Atena Editora, 2009.

LIPOVETSKY, Gilles. O Império de efêmero. São Paulo: Companhia de Bolso, 2009.

MALERONKA, Wanda. Fazer roupa virou moda: um figurino de ocupação da mulher (São Paulo 1920 - 1950). Editora Senac: São Paulo, 2007.

MOUTINHO, Maria Rita; VALENÇA, Máslova Teixeira. A moda no século XX. Rio de Janeiro: Editora Senac Nacional, 2005.

MULHER UOL. Zuzu Angel: peças originais. Disponível em:

<http://mulher.uol.com.br/moda/album/zuzuangelvestidosoriginais_album.htm\#fotoNav= 7>. Acesso em: 31 de out. de 2014.

NORMAN, Donald A. Design emocional: por que adoramos (ou detestamos) os objetos do dia-a-dia. São Paulo: Rocco, 2008. 
PERROT, Michelle. Praticas da Memória Feminina. Revista Brasileira de História. São Paulo: Anpuh, v. 9 n.18, ago./ set. de 1989.

PETIT, Pere; CUÉLLAR, Jaime. O golpe de 1964 e a instauração da ditadura civil-militar no Pará: apoios e resistência. Estudos Históricos. Rio de Janeiro, v. 25, n.49, p.169-189, jan/jun 2012.

PRADO, Luís André; BRAGA, João. História da moda no Brasil. das influências às autorreferências. 2.ed. São Paulo: Disal, 2011.

PRADO, Maria Ligia; FRANCO, Stella Scatena. Participação feminina no debate público brasileiro. In: PINSKY, Carla Bassanezi; PEDRO, Joana Maria. (Orgs.). Nova história das mulheres no Brasil. São Paulo: Contexto, 2012. p. 104-217.

REIS, Daniel Aarão. Ditadura, anistia e reconciliação. Estudos Históricos. Rio de Janeiro, v.23, n.45, p.171-186, jan./jun., 2010.

SILVA, Priscila Andrade. A moda Zuzu Angel e o campo do design. 2006, oof. Dissertação (mestrado em Design) - Pontificia Universidade Católica, Mestrado em Design., Rio de Janeiro, 2006.

SIMMEL, Georg. Filosofia da moda e outros escritos. Texto \& Grafia. Lisboa, 2008.

SOIHET, Rachel. Mulheres e biografia: significados para a história. Locus, Juiz de Fora, v. 9, n. 1, p. 33-48, 2003. Disponível em:< http://www.ufjf.br/locus/edicoesanteriores/volume-9-numero-1-jan-jun-2003/mulheres-e-biografia-significados-para-ahistoria-rachel-soihet/>. Acesso em: abr.2011

ZIMMERMANN, Maíra. Jovem Guarda: moda, música e juventude. Estação das Letras e Cores, São Paulo, 2013.

ZUZU Angel. [Filme]. Brasil/2006. Direção: Sérgio Resende. Duração: 108 min. 
Recebido em 26/03/2015 Aprovado em 05/08/2014

Universidade do Estado de Santa Catarina - UDESC

Programa de Pós-Graduação em História - PPGH

Revista Tempo e Argumento

Volume 07 - Número 15 - Ano 2015

tempoeargumento@gmail.com 